\title{
The potential geographical accessibility to public hospitals for the population in Bucharest' proximity
}

\author{
Alexandra Cioclu ${ }^{* 1}$ \\ ${ }^{1}$ University of Bucharest, Romania
}

Access to health services is essential for ensuring a fundamental human right: the right to health care. Traditional accessibility methods do not consider traffic changes and possible infrastructure works and do not always reflect the actual travel time to the nearest hospital. This study tries to measure the potential access to hospitals of the population from the proximity of Bucharest, an area overlapping Ilfov County, using API (Application Program Interface). Two scenarios were considered. The first represents accessibility in the morning, an interval with heavy traffic, and the second represents accessibility in the evening, an interval without heavy traffic. The results confirm that Ilfov County has good accessibility to public hospitals, with over $60 \%$ of the population travelling less than 30 minutes to the nearest hospital. The proximity of Bucharest makes it possible for residents to access hospitals in that area quickly. The findings provide a scientific basis for local authorities to optimize access to hospitals and planning resources.

Key Words: health care, hospital, potential accessibility, Ilfov County, Bucharest, Romania

Article Info: Received: April 3, 2020; Revised: April 24, 2021; Accepted: May 15, 2021; Online: May 31, 2021.

\footnotetext{
"Correspondence address

Address: Faculty of Geography, University of Bucharest, N. Bălcescu Av., no. 1, Bucharest, 010041, Romania

Phone: +400725713529| Email: alexandra_cioclu@yahoo.com
}

(C)2021 Human Geographies; The authors

(6) $(0)$ This work is licensed under a

Creative Commons Attribution 4.0 International License. DOI:10.5719/hgeo.2021.151.5 


\section{Introduction}

Accessibility is the ease with which a place can be accessed/reached (Bavoux et al., 2005; Spiekerman \& Wegener, 2006). It is a continuous function, a unit of measurement for accessible places. Access depends on several factors, among which distance occupies a special place. The notion of accessibility is based on two key concepts (Rodrigue et al., 2006). The first is when its relative position is estimated in relation to the transport networks, as they underlie mobility. The second is the distance (or, more generally, the distance between places), which derives from the connectivity between places, and the possibility of two places to be connected by transport networks. In both cases, the study of networks, as a primary factor in spatial analysis, proves to be paramount in assessing accessibility.

Network analysis provides an opportunity to understand the relationships between places and reiterate that they are not independent elements (Pumain \& Saint-Julien, 2004). The networks studied in geography represent sets of lines that ensure the connection between various places, referring mainly to the support network or infrastructure, most often material. There is also the network of exchanges or the drawn network of flows, which designates traffic in a specific support network. Accessibility is ultimately an indicator of the spatial structure, as it takes into account both places and inequalities produced by distance; due to the spatial structure, two different places of equal importance will have different accessibility (Rodrigue et al., 2006). Higgs (2004) distinguish between access to healthcare and available access; the former may result from the availability of services, the latter refers to the resources needed by the individual to overcome financial barriers, socio-cultural and use the service it needs.

The distance from the medical units is important for patients, doctors and other employees in the health system (Albert et al., 2000). Wang (2006) classified access into two dichotomous dimensions, potential vs existing and spatial vs spatial. Existing accessibility focuses on the actual use of a service, while significant potential accessibility is likely to be a service, and spatial access is linked to many demographic and socio-economic variables. Spatial accessibility is the only dimension of accessibility to services of general interest, along with other issues such as financial accessibility or quality of services.

Previous studies have shown that spatial accessibility to different types of services of general interest influences, sometimes quite strongly, the addressability of the population to that service. For example, Hiscock et al. (2008) demonstrated, using data from a New Zealand population health survey, that the addressability of the population to family doctors, blood pressure measurement and pharmacy attendance are inversely related to the distance from these services: the longer the distance to the family doctors' offices, the less the population uses primary medical services. Pierce et al. (1998), analyzing a sample of the rural elderly population in Missouri (USA) diagnosed with myocardial infection, identified that those living further than $96.5 \mathrm{~km}$ from the nearest medical centre call less for the necessary cardiovascular interventions than those at shorter distances. For the state of Illinois (USA), Wang (2006) identified an association between late-stage 
breast cancer diagnosis and low spatial accessibility to primary care. Gage \& Calixte (2006) found an increase in the addressability of prenatal health care services when medical centres are less than $5 \mathrm{~km}$ from the beneficiary population.

Ensuring a high degree of accessibility to essential services (health care, supply and services, cultural, educational, recreational) is critical, especially for an area with a high territorial dynamic, such as the metropolitan area of Bucharest, which includes all localities of Ilfov County. Good connectivity and accessibility in the metropolitan area are necessary to ensure the physical and mental health of citizens (Tyrväinen et al., 2007; Sotoudehnia \& Comber, 2011), as well as to increase the attractiveness of investments (ESPON, 2013). In the context of spatial development, the quality of the transport infrastructure in terms of capacity, connectivity, speed determines the advantage of an area (Spiekermann \& Wegner, 2007). Also, in addition to the limitations imposed by the transport infrastructure, the geographical accessibility of medical services is uneven due to the territorial distribution of medical services and consumers. While early studies on the geographical accessibility of medical services were based on measuring the distance between consumers and services in a straight line (Euclidean), recent studies measure the distance in kilometres and minutes from the city centre to the nearest hospital (taking into account certain measures and aspects such as transport infrastructure for measuring distance in kilometres, speed limits and type of means of transport for measuring travel time), thus having a better validity, as accessibility quantifies the number of medical services available in comparison with the number of potential consumers of these services. In reality, the situation regarding the geographical accessibility of medical services is slightly different because: consumers have their particular driving style (for example, respecting speed limits), owning a vehicle (or in their absence opting for public transport), experience different travel conditions (depending on: day, time, local traffic conditions and weather), do not all leave from the same point in the locality, opt for different routes or choose to move to a specific hospital (for which they have a certain affinity) and not the nearest (Delamater et al., 2012). Thus, transportation is a basic but necessary step for ongoing healthcare and medication access, particularly for those with chronic diseases (Syed et al., 2013).

Despite a relatively large literature on the use of GIS in health applications in general, few have provided an overview of the current state of play concerning the application of GIS-based measures of access in the health arena and identified potential avenues for further research (Higgs, 2004). The studies where GIS technology is used in order to identify communities that lack adequate access to medical assistance are useful in the sense that they may serve as foundations for local administration's interventions aiming to improve accessibility (Merciu et al., 2013). Travel time is one of the most suggestive and used indicators for measuring ease of access (García-Albertos et al., 2018; Weiss et al., 2018). The traditional method for estimating travel time is mainly based on GIS analysis of origindestination (OD) matrices, which require large amounts of geographic data (Li et al., 2017; Lee et al., 2017). Through the development of the Internet, web mapping platforms such as OpenStreetMap (OSM) and Google Maps are widely 
used by researchers for their advantages of open access and analysing existing transport networks (Socharoentum \& Karimi, 2015). These web mapping platforms can provide essential geographic data and have a solid spatial analysis capability through an application programming interface (API) (Kobayashi et al., 2010).

In Romania, a series of studies analyze population access to health services at the regional level. Mareci (2008) analyzes population access to medical services in the North East region of Romania and remarks that in situations when a village is situated at similar distances from two hospitals, most people will tend to travel towards the bigger or the most important one. Dumitrache et al. (2020) measured the access time of the population to hospitals in Romania using API. An index of spatial accessibility was calculated, considering the rank of hospitals and travel time, and its values showed low accessibility for the population living in rural or remote areas. The basic factor involved in the issue of healthcare access is the spatial distribution of healthcare units (supply) and population (demand) (Naghawi, 2012). For health professionals, assessing the potential health needs of the population is vital in describing disease patterns, highlighting areas with the greatest needs, optimizing resources and influencing national and regional policies (Wright \& Williams, 1998). Public hospitals still polarize healthcare activity in Romania, with over $25 \%$ of the population hospitalized yearly, thus access to hospitals is very important (Dumitrache et al., 2016).

This paper focuses on the spatial accessibility of the population living in the proximity of Bucharest to public hospitals. It is based on actual travel time from each locality to the nearest hospitals, measured at two different time slots: morning, between 9:00-11:00 (peak time) and evening, between 21:00-23:00 (non-peak time).

\section{Methodology}

The analysis explored the potential geographical access of the population from the proximity of Bucharest, the capital of Romania, to public hospitals. The study area includes 32 rural settlements and 8 cities on a surface of $1,583 \mathrm{~km}^{2}$ overlapping from an administrative point of view with the territory of Ilfov County. According to data from the National Institute of Statistics, in January 2020, Ilfov County registered 451,839 inhabitants, of which 54\% lived in rural areas and $46 \%$ in urban areas. Contrary to the national trend of continuous population decline under the influence of demographic ageing and labour emigration, the population in Ilfov County has recorded a steady increase of $33 \%$ since 2007 and is expected to continue to grow until 2060. Additionally, the study area has the most complex network of highways, national and county roads in Romania. Most of the higher-ranking roads converge in Bucharest. Radial connections are made through the belt of Bucharest and discontinuous county roads (DJ100, DJ401A or DJ101) totalling 448,876 km of county roads, out of 
which $34 \%$ were modernized in 2019 , less than $7 \%$ of them were still paved, but the overall quality of road infrastructure is mostly good.

Knowledge of spatial accessibility in public hospitals is vital for developing health plans and strategies (Brabyn \& Skelly, 2002). This is a challenge in Romania in general but is even more difficult in an area with accelerated spatial and demographic dynamics, as is the area surrounding Bucharest. Some methods of measuring accessibility are challenging to apply in Romania due to the lack of data. Although many institutions collect data on the health system functioning and healthcare activities, there are difficulties in using them for planning and decision-making due to their low reliability and fragmentation (Dumitrache et al., 2020).

Starting from the spatial distribution of hospitals, a significant parameter of potential geographical accessibility was calculated: the time to the nearest hospital using the Google Distance API Matrix. Travel time estimates are recognized as more appropriate measures of travel effort than linear distances (Barbieri \& Jorm, 2019). The use of time and the relationship between space and time has an important impact on choice, so travel time is more important than travel distance (Brabyn \& Skelly, 2002).

This study used territorial administrative units as basic units for travel time to the nearest hospital. The population at the level of the territorial administrative unit varies between 2,682 and 41,306. The National Institute of Statistics provides data on the total population of a territorial administrative unit without capturing the spatial spread. As such, the territorial administrative units from Ilfov County were geocoded, and the resulting centroid was considered to represent the total population of the settlement. A total of 42 units were taken into account to calculate time to the nearest hospital. Because of the high probability of death in children under 5 years old and the ageing population increases the need for medical services, the territorial distribution of age groups $0-4$ years and over 65 years was analyzed, using data available on the website of the National Institute of Statistics (2020). Also, data from the Diagnosis Related Groups system (DRG) site managed by the National School of Public Health, Management and Professional Development (NSPHMPD) was used to measure hospitalized morbidity.

Data on the number and type of hospitals in the study area were taken from the National Diagnosis Related Groups system (DRG, 2020) and the updated websites of each hospital. During the hospital selection process, the legal property regime was taken into account by choosing only public hospitals. Due to the proximity of the capital, the emergency hospitals in Bucharest were also taken into account because the short distance determines the inhabitants of Ilfov County to go to the emergency hospitals in Bucharest rather than the hospitals located nearest to them. 11 hospitals were selected, 3 from Ilfov and 9 from Bucharest and accessibility was measured for the 40 territorial administrative units on the territory of Ilfov County. Each hospital was geolocated using Google Maps, and if the exact location was not found, it was located manually. ArcGIS Pro 2.5.0 software was used to geolocate hospitals. 
The study aims to measure accessibility only for hospitals because statistics show that many cases that family doctors or outpatients could successfully solve are treated in hospitals in Romania (Petrescu \& Ioncică, 2012). Thus, Romania reaches a higher rate of hospitalizations than in other European countries (European Observatory on Health Systems and Policies, 2019). But this is optimal for meeting the health needs of the population, as hospital spending increases, staff are deficient, and the quality of services is often challenged (Chirilă \& Severin, 2018).

Two scenarios were considered in determining population accessibility to hospitals. The first scenario represents accessibility in the morning, between 9:00 and 11:00, an interval with heavy traffic, and the second represents accessibility in the evening, between 21:00 and 23:00, an interval without heavy traffic. In this regard, Google Maps Application Programming Interface (API), a service that provides the distance and time required from the point of origin to the destination, was chosen. An advantage is the integration of several factors that can influence traffic, such as congestion or accidents and the proposal of detours (García-Albertos et al., 2018). Also, another advantage of the Google Maps Application Programming Interface (API) is the minimal data preparation and the need for minimal GIS knowledge (Wang \& Xu, 2011). The chosen means of transport was the car, and the plugin used was Create Drive Time Areas. The selected time was Monday; the direction was towards the facility, and the areas from different points were overlapped.

The minimum travel time generated served as an indicator for measuring spatial accessibility. Based on the travel time for the two scenarios, peak and nonpeak, from each location to the nearest hospital, accessibility was divided into several levels using a time scale with an interval of 10-20, 20-30, 30-40, 40-50, >60 minutes, considering that a difference of 10 minutes is suitable for the study area. However, this exploratory study has limitations. The author had to adapt the method to the available data. The accuracy of the results may be influenced by the lack of the exact address of the patients, the chosen route, the chosen means of transport, speed and potential patients from vulnerable groups will not be able to use the car to the nearest hospital (Kelly et al., 2016). Moist et al. (2008) reported that increased time when using public transportation contributed to the lack of patients from renal dialysis sessions. The chosen day is important because traffic may be less congested, and the speed may be higher at the end of the week (Li et al., 2011). In addition, there are possible traffic events, accidents or works on transport infrastructure that may change travel times.

\section{Results and Discussion}

\section{Population' potential healthcare need}

The age-based model and the hospitalized morbidity was considered to assess the population potential needs. The population groups over 65 years and the group 
0-4 years were considered the primary consumers of medical services because they are the most vulnerable. According to data from the Diagnosis Related Groups system (DRG), the proportion of cases in 2020 in the study area for the 0-4 years category was $5.6 \%$, and for the over 65 years category was $26.4 \%$, a sign that these two categories have a high need for medical services.

Figurel shows the main diseases that require hospitalization and are at risk of morbidity: the circulatory system, respiratory system, muscle, complications associated with pregnancy and childbirth, but also diseases of the nervous system and digestive system. Risk factors for these diseases include a poor diet, tobacco use, alcohol consumption, and low physical activity. Romania is below the European average, $62 \%$ compared to $44 \%$, in terms of physical activity, and tobacco consumption is a public health issue (European Observatory on Health Systems and Policies, 2019). Between 2015 and 2020, there have been increases in the number of patients suffering from diseases of the musculoskeletal and digestive system. A particularity is represented by the number of mental disease patients, which dropped dramatically in 2015, only to increase again in 2020 .

Population ageing is one of the factors recognized to cause an increase in the needs and implicitly demand for health services (Panait, 2011). Population over the age of 65 represents $12.68 \%$ of the total population, while the $0-4$ age group represents $5.84 \%$. If most of the elderly are concentrated in the northern part of the area, the most significant number of children are in the immediate vicinity of the capital, a situation justified by the phenomenon of suburbanization (through which young people who start their families choose to be located in that part of the outskirts of the capital where the most significant economic development has taken place in recent years).

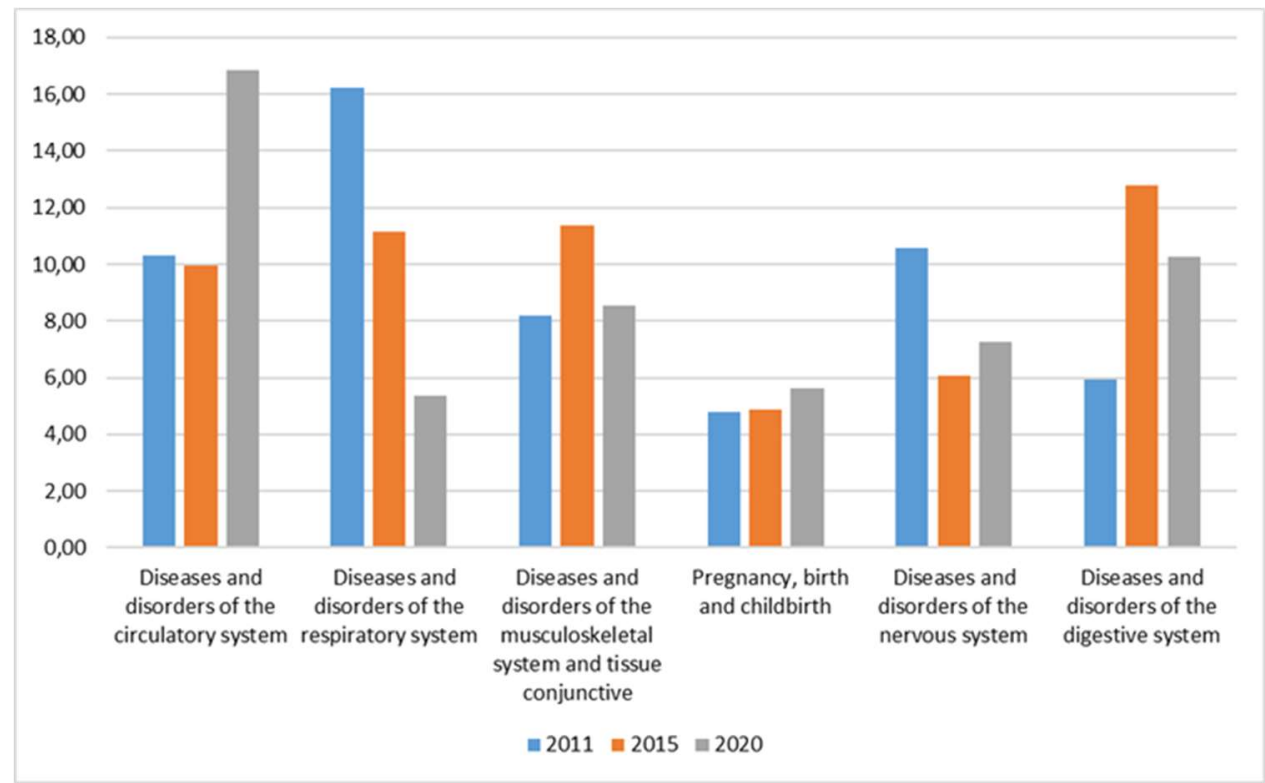

Figure 1. Hospitalized morbidity between $2010-2020$ 


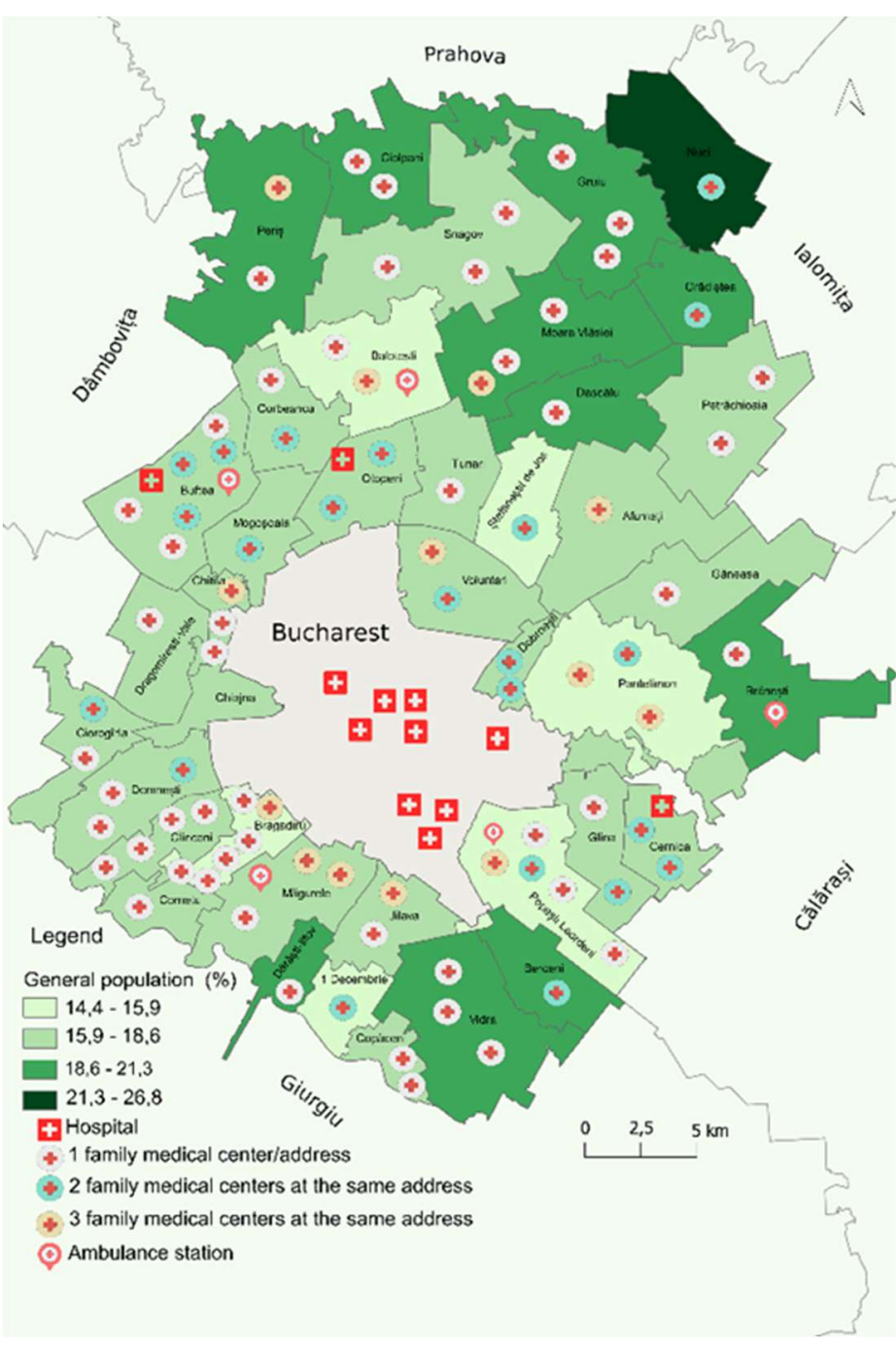

Figure 2. Population over 65 years + population 0-4 years / total population (at locality level)

Thus, if the hospitals in the capital can be accessed for the potential medical needs of children, the same cannot be said about the needs of the elderly since the distance travelled to the nearest hospital being inevitably longer. Family medical offices exist in each territorial administrative unit but are accessed only for basic services. Also, Ilfov County is equipped with ambulance stations, so in case of emergencies, the population can call an ambulance that arrives in a few minutes, depending on the caller's area.

Most of the territorial administrative units in Ilfov County fall into the first and second category (Figure 2). High percentages of potential consumers highlight a greater need for health services. Although the southern half has a lower share of potential consumers compared to the northern half, it is there that most family medical offices are located. The elderly demand for health services increases in 
accordance with the proportion of the elderly in the total population (Russel, 1981), a situation encountered in the northern part of the study area. There is no concordance between the potential need for health services and infrastructure; thus, patients are forced to travel a greater distance to the nearest hospital. As the elderly are a significant part of the potential consumers, as they tend to access health services more frequently, it is necessary to improve their access to health services. An approach that includes the active collaboration of the health, social work, rural/urban development and legal sectors is needed to prevent and control the health problems of the elderly.

Chirilă \& Severin (2018), in a study related to the needs of the population through the use of health services, found that in the case of primary care, $20 \%$ of respondents believe that the use of health services and resources does not reflect their needs. In the case of ambulance services, the overwhelming opinion, $77 \%$, is that the use of health services and resources reflects the population's needs. The fact that over $50 \%$ of respondents consider that the use of health services does not reflect at all or only to a small extent the needs of the population is not surprising, given the problems faced by this compartment of the health system: insufficient budget (below the EU average), staff (especially in rural areas), and the fact that the infrastructure requires multiple investments. In a similar study, Cosma et al. (2020) reveal that the most satisfied patients are: older, with a low level of education or with low incomes.

\section{Hospital role as the main provider of medical services}

Hospitals are an essential component of the health care system and central to the process of reform, and yet, as institutions, they have received remarkably little attention from policy-makers. Despite numerous reforms to reduce hospital capacity and strengthen primary care, the hospital has proven to be a complex institution, resistant to change, which continues to dominate the landscape of care in Romania (Dumitrache et al., 2020).

Depending on their location, hospitals are classified into county hospitals, municipal and town hospitals, communal hospitals. Depending on the specific pathology, hospitals are classified into general hospitals (which have at least 3 of the 4 basic specialities, respectively internal medicine, paediatrics, obstetricsgynaecology and surgery), emergency hospitals (with a complex structure of specialities, appropriate medical equipment, specialized personnel, covering the needs of a population from vast territories), specialized hospitals (which offers services in a certain specialization), hospitals for patients with chronic diseases. In terms of ownership, hospitals are classified into: state hospitals, which can be public or private hospitals, owned by the state or local authorities, private hospitals owned by other legal entities, and mixed hospitals (Romanian Government, 2015).

The medical infrastructure in the analyzed area is made out of 3 public hospitals (in Ilfov County) and 9 emergency hospitals (in Bucharest). In addition to hospitals, the public health system is mainly represented by facilities with local 
service role, such as family medical offices, dental offices, specialized offices, pharmacies. As reported by the National Institute of Statistics, in 2020, there were 164 family medical offices and 915 doctors in Ilfov County. The ratio between the number of offices and the total population of Ilfov County shows that a family doctor has approximately 2,050 possible patients. At the same time, it should be noted that $60 \%$ of the study area has access to doctors who are entirely part of the private sector which is not exactly beneficial for the population if those doctors have not concluded a signed with the Ilfov County Health Insurance House. In 2011 , there was an accentuated process of privatization of family medical offices, specialized offices, pharmacies and dental offices, so that in 2018, the majority of the county's population was served by private infrastructure. This limits the responsibility and capacity of public administrations to ensure the quality of medical services provided and may increase the costs of medical services.

According to the National Institute of Statistics, in 2020, in Ilfov County, there were, on average, 3 beds in public hospitals per 1,000 inhabitants. This value is not only below the national average of 5 , but places Ilfov County in $38^{\text {th }}$ place out of the 42 counties. Thus, the inhabitants of Ilfov County are also dependent on Bucharest's hospital infrastructure. The situation is even more worrying when considering the evolution of beds in public hospitals, which decreased significantly since 2009. Therefore, public authorities are demanding efforts to expand existing hospitals or create new hospitals to serve the entire county. On the other hand, the number of beds in private hospitals increased significantly, from 16 in 2007 to 141 in 2018 . However, most private hospitals offer services dedicated to certain types of diseases and do not necessarily have a complex infrastructure for diagnosing and treating a wide range of diseases. In Romania, the hospital network underwent substantial restructuring after 1990, aiming to decentralise it and reduce costs. The most important reforms occurred between 2009-2013 (Ciocan, 2016). Underfunding of the health care system has led to the failure of reform measures and unequal territorial distribution of medical staff, which affects the population's access to medical services (Dumitrache et al., 2020).

\section{Differentiation in access to medical services from a temporal point of view}

A major assumption in many studies is that patients will use their nearest health facility, but some studies have found that this may be not necessarily the case (Gibbs, 2005). A report prepared by the Institute of Medicine in 1993 defined access to medical services as the timely use of services to achieve the best results for health, geographical accessibility being along with availability, acceptability, accommodation and accessibility one of its components (Millman, 1993). The elderly and children are the most affected because they have to travel relatively long distances to receive treatment or for various medical emergencies. Inadequate transport infrastructure, lack of public transport, and transport costs contribute to these vulnerable groups increasing dissatisfaction with the medical services. 
The main restrictive factor in the accessibility to medical services the travel time to the nearest hospital and makes it necessary to study it both during peak periods (09:00 -11:00) and non-peak (21:00 - 23:00). According to European Observatory on Health Systems and Policies (2019), in 2017, 4.7 \% of Romanians reported unmet needs for medical care because of cost, distance or waiting time, compared to an average of $1.7 \%$ in the EU. As is the case in most EU countries, those with the lowest incomes report the most significant unmet needs. In 2017 around $6.5 \%$ of Romanians from low-income households said they had foregone medical care for financial reasons, compared to $2.3 \%$ in the EU. However, this was better than the $14.5 \%$ reported in 2010. Dumitrache et al. (2020) note that $17 \%$ of Romanians live within 30-90 minutes' drive time to a hospital, while those requiring a longer drive time to the closest facility represent less than $0.2 \%$.

Following the measurements done, it turned out that in the morning (between 09:00 and 11:00), 35\% of the population has access in 10-20 minutes to the hospitals in Ilfov County, and only $10 \%$ of the population has access to the emergency hospitals in Bucharest in 10-20 minutes (Table 1).

When analyzing the potential access to hospitals in the evening, between 21:00 and 23:00 (interval without heavy road traffic), and comparing it with morning time access, the percentage of the population with a high degree of accessibility of medical services has increased, even with $10 \%$ and the over 60 minutes interval in access to hospitals in Bucharest has disappeared (Table 2).

Table 2. Population access to hospitals (morning)

\begin{tabular}{lcccc}
\hline & \multicolumn{2}{c}{ Ilfov Hospitals } & \multicolumn{2}{c}{ Bucharest Hospitals } \\
Evening & Population & \% total population & Population & $\%$ total population \\
\hline $10-20 \mathrm{~min}$. & 158,209 & 35 & 45,202 & 10 \\
$20-30 \mathrm{~min}$. & 49,722 & 11 & 99,445 & 22 \\
$30-40 \mathrm{~min}$. & 113,006 & 25 & 94,925 & 21 \\
$40-50 \mathrm{~min}$. & 90,405 & 20 & 113,006 & 25 \\
$50-60 \mathrm{~min}$. & 36,162 & 8 & 54,243 & 12 \\
$>60 \mathrm{~min}$. & 4,52 & 1 & 45,202 & 10 \\
\hline
\end{tabular}

Source: Author's calculations

Table 2. Population access to hospitals (evening)

\begin{tabular}{lcccc}
\hline & \multicolumn{2}{c}{ Ilfov Hospitals } & \multicolumn{2}{c}{ Bucharest Hospitals } \\
Evening & Population & \% total population & Population & \% total population \\
\hline $10-20 \mathrm{~min}$. & 180,810 & 40 & 54,243 & 12 \\
$20-30 \mathrm{~min}$. & 49,722 & 11 & 135,608 & 30 \\
$30-40 \mathrm{~min}$. & 149,168 & 33 & 90,405 & 20 \\
$40-50 \mathrm{~min}$. & 45,202 & 10 & 103,966 & 23 \\
$50-60 \mathrm{~min}$. & 27,121 & 6 & 67,804 & 15 \\
$>60 \mathrm{~min}$. & 2,260 & 0.5 & - & - \\
\hline
\end{tabular}

Source: Author's calculations 


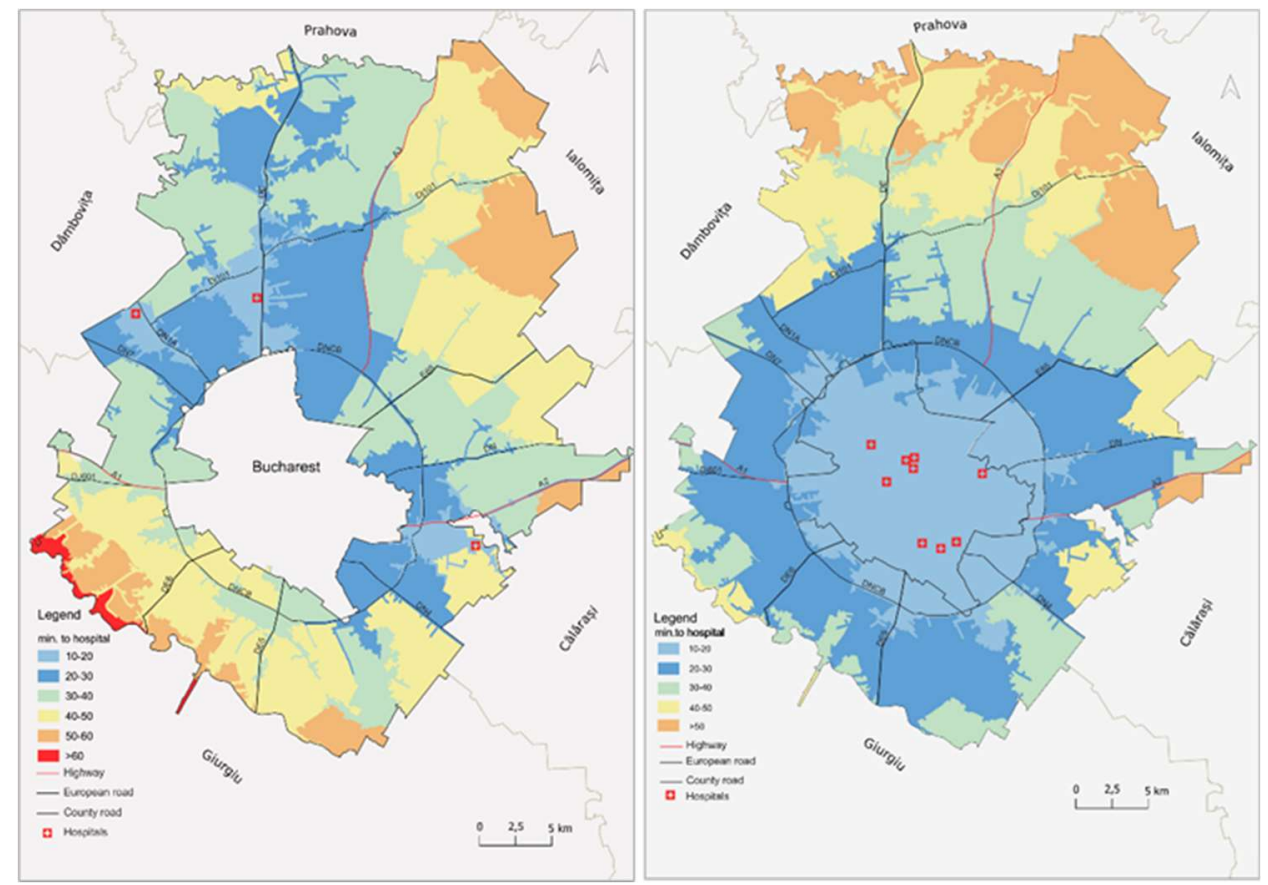

Figure 3. Potential access to hospitals in the morning in Ilfov County (a.) and Bucharest (b.)

The urban localities have the best degree of accessibility of medical services in the morning as well as most of the rural localities up to a distance of about 25 or even 30 kilometres depending on the state of the infrastructure or local traffic conditions. Also, not all the population of the study area owns a car, so these distances are potential; there are also people who are forced to use public transport, needing more time to get to that nearest hospital (they are conditioned by both public transport routes and its schedule).

The urban area inhabitants and those close to hospitals have the best accessibility. From this point of view, the inhabitants of the northern area of Ilfov County are the most disadvantaged, needing more than 30 minutes to reach the nearest hospital in both moments. Although proximity to the capital is a considerable advantage, the development level differs considerably from locality to locality. Economic activity is concentrated in specific areas, and social problems still persist. They include marginalization and exclusion, based on territorial positioning and lack of accessibility (the case of small communes in the northeast of the county), discrimination based on ethnicity (the case of ethnic communities Roma) or economic causes (financial constraints due to the need to commute to Bucharest). These factors also influence the population's access to hospitals, as certain ethnic groups' level of development, and limited financial resources also affect accessibility. The analysed area enjoys the most complex network of highways, national and county roads in the country. Most of the higher-ranking roads converge towards Bucharest, and the radial connections are made through the city belt and some discontinuous county roads (DJ100, DJ401A or DJ101). 

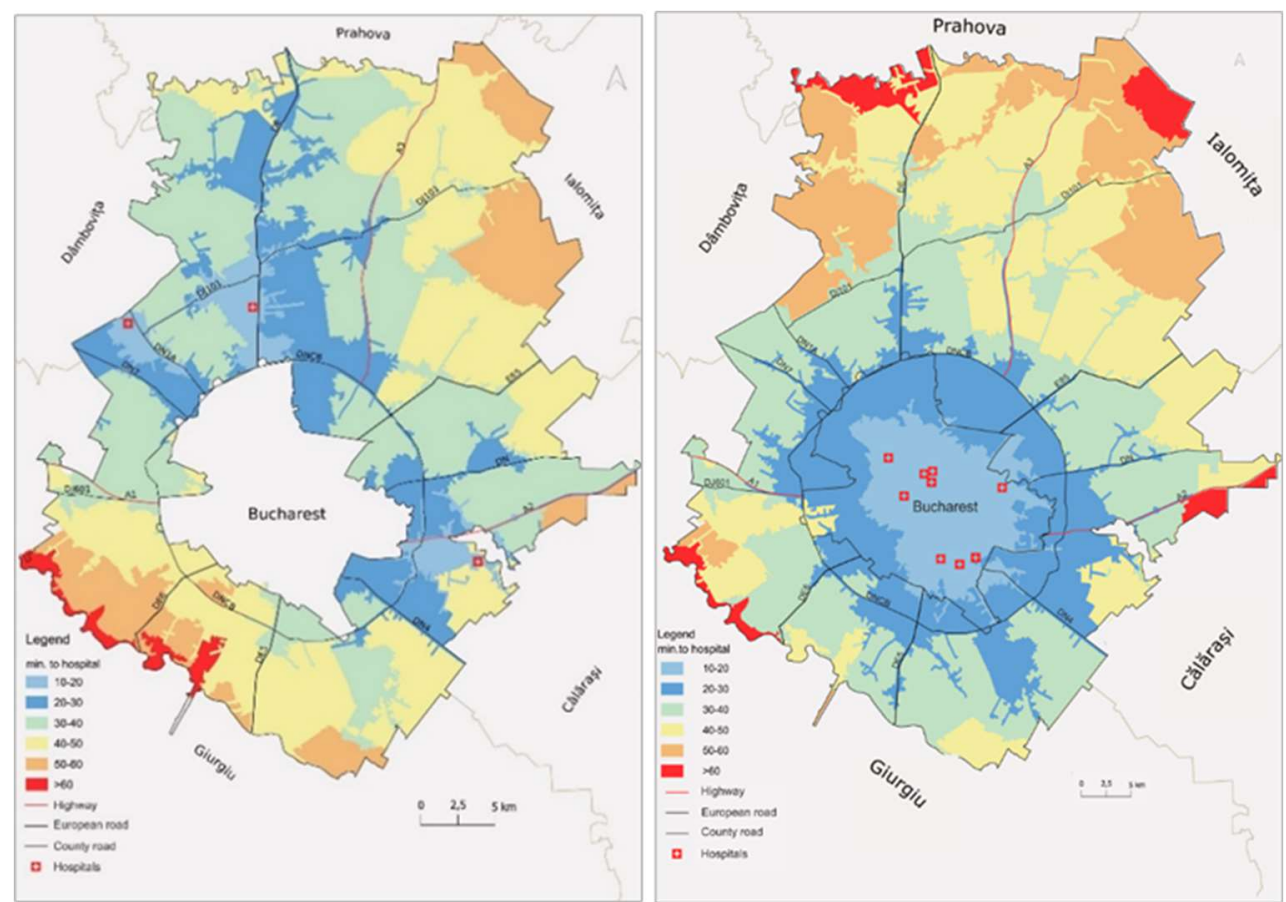

Figure 4. Potential access to hospitals in the evening in Ilfov County (a.) and Bucharest (b.)

Considering the synergistic relationship between Ilfov County and Bucharest, including their territorial influence, the importance of the main communication channels exceeds the county level. In the medium term, the most important connection is DN4, through which the inhabitants of the functional urban area can access the proximity of Bucharest. The following connections in order of importance are A1, A2, A3 and DN2; because the highways (especially A2) do not always provide connections to the localities they cross. Therefore, in reality, DN3 manages to serve more localities than A3. In the long run, taking into account the population under the age of 15, DN4 together with DN2, A1 and DN765 become the most important links. In this sense, strengthening the least performing connections with the settlements in the south, northwest and northeast should be an important issue for the near future.

\section{Conclusions}

This study explores the potential need of the population for medical services and spatial accessibility to public hospitals. Google Maps API navigation services are suitable for providing real-time data on distance and travel time. The data were used for both peak and non-peak hours to compare spatial accessibility during high and low traffic. In this study, only public hospitals were considered, and the 
resulting times allowed the identification of existing differences between the chosen moments.

The results confirm that Ilfov County has a good accessibility to public hospitals, with over $60 \%$ of the population living less than 30 minutes to the nearest hospital, and the proximity of Bucharest makes it possible for residents to access hospitals located in the capital city of Romania.

As the research showed, the population's access to medical services is influenced by the chosen travel time. In the peak interval - morning, the accessibility of the population to medical services decreases as a result of heavy traffic. In the evening, the non-peak interval, the accessibility of the population to medical services increased by up to $10 \%$. This shows that traffic significantly affects the potential accessibility to medical services. The chosen time for travel, distance, the chosen means of transport but also the speed are the main factors that influence the accessibility of the population to medical services. The northern part of the study area has the greatest potential need for health services, but it also has lower accessibility, as the population from that area needs 50-60 minutes to reach the nearest hospital.

This research contributes to a better understanding of the geographical accessibility of the population to public hospitals, helping to identify polarization trends. The results obtained can help decision-makers develop urban planning strategies and optimize investments in health care infrastructure. Future studies will consider the use of other means of transport and other time slots.

\section{References}

Albert, W.M., Gesler, W.M. and Levergood, B. (eds) (2000), Spatial Analysis, GIS and Remote Sensing Applications in the Health Sciences, Ann Arbor Press, Chelsea, Michigan, p. 231.

Barbieri, S. and Jorm, L., (2019). "Travel time to hospitals in Australia", Scientific Data, vol. 6, no. 248.

Bavoux, J.J., Beaucire, F., Chapelon, I. and Zembri, P. (2005), Géographie des transports, National Committee of Geography of Belgium, Société Royale Belge de Géographie, Paris, p. 232.

Brabyn, L. and Skelly, C., (2002), "Modeling population access to New Zealand public hospitals", International Journal of Health Geographics, vol. 1, no. 3.

Chirilă, S. and Severin, B. (2018), "Reflecting population's needs using health services - the family physicians' perspective", Medic.ro, vol. 123, no. 3, p.14-18.

Ciocan, M. (2016), "Aspecte privind reforma serviciilor medicale spitalicești din România", Human Rights Journal, no. 3, p. 18-26.

Delamater, P.L., Messina, J.P., Shortridgem, A.M. and Grady, S.C., (2012), "Measuring geographic access to health care: raster and network-based methods", International Journal of Health Geographics, vol. 11, no. 15.

Diagnostic Related Groups (DRG) (2020), Indicators of hospitalization circumstances, 3 April 2021, http://www.drg.ro/index. 
Dumitrache, L., Nae, M., Dumbrăveanu, D., Simion, G. and Suditu, B. (2016), "Contrasting Clustering in Health Care Provision in Romania: Spatial and Aspatial Limitations", Procedia Environmental Sciences, vol. 32, p. 290-299.

Dumitrache, L., Nae, M., Simion, G. and Taloș, A.M. (2020), "Modelling Potential Geographical Access of the Population to Public Hospitals and Quality Health Care in Romania", International Journal of Environmental Research and Public Health, vol. 17, no. 22.

ESPON (2013), Growth Poles in South-East Europe - Emergence of Growth Poles Network in South-East of Europe, Applied Research 2013/2/19, Final Report, 3 April 2021, shorturl.at/aqxJM.

European Observatory on Health Systems and Policies (2019), State of Health in the EU Romania: Country Health Profile, OECD Publishing: Paris, France.

Gage, J.A. and Calixte, M.G. (2006), "Effects of the physical accessibility of maternal health services on their use in rural Haiti", A Journal of Demography, vol. 60 , no. 3 .

García-Albertos, P., Picornell, M., Salas-Olmedo, M.H. and Gutiérrez, J. (2018), "Exploring the potential of mobile phone records and online route planners for dynamic accessibility analysis, Transportation Research Part A: Policy Practice, vol. 125, p. 294-307.

Higgs, G. (2004), "A literature review of the use of GISbased measures of access to health care services", Health Services E Outcomes Research Methodology, no. 5, p. 119-139.

Hiscock, R., Pearce, J., Blakely, T. and Witten, K. (2008), "Is Neighborhood Access to Health Care Provision Associated with Individual-Level Utilization and Satisfaction?", Health Services Research, no. 43, p. 2183-2200.

Kelly, C., Hulme, C. and Farragher, T. (2016), "Are differences in travel time or distance to healthcare for adults in global north countries associated with an impact on health outcomes? A systematic review", BMJ Open, vol. 24, no. 6, p. 11 .

Kobayashi, S., Fujioka, T., Tanaka, Y., Inoue, M., Niho, Y. and Miyoshi, A. (2010), "A geographical information system using the Google Map API for guidance to referral hospitals", Journal of Medical Systems, vol. 34, no. 6, p.11571160 .

Lee, M., Barbosa, H., Youn, H., Holme, P. and Ghoshal, G. (2017), "Morphology of travel routes and the organization of cities", Nature Communication, vol. 8, no. 1.

Li, Q., Zhang, T., Wang, H. and Zeng, Z. (2011), "Dynamic accessibility mapping using floating car data: a network-constrained density estimation approach", Journal of Transport Geography, vol.19, no. 3, p. 379-393.

Li, R.Q., Dong, L., Zhang, J., Wang, X.R., Wang, W.X., Di, Z.R. and Stanley, H.E., (2017), "Simple spatial scaling rules behind complex cities", Nature Communication, no. 8.

Mareci, A. (2008), "The Degree of Accessibility to Health Care - Issues Concerning the North-Eastern Population of Romania", Human Geographies, vol. 2, no. 1. 
Merciu, C., Stoian, D., Merciu, G. and Saghin, I.M. (2013), "Using GIS for calculating the accessibility to hospitals in the city of Bucharest and its metropolitan area (Romania)", Geograhica Pannonica, vol. 17, no. 4.

Millman, M. (ed) (1993), Access to Health Care in America, Institute of Medicine, The National Academies Press, Washington DC.

Moist, L.M., Bragg-Gresham, J.L., Pisoni, R.L., Saran, R., Akiba, T., Jacobson, S.H., Fukuhara, S., Mapes, D.L., Rayner, H.C., Saito, A. and Port, F.K. (2008), "Travel Time to Dialysis as a Predictor of Health-Related Quality of Life, Adherence, and Mortality: The Dialysis Outcomes and Practice Patterns Study (DOPPS)", American Journal of Kidney Diseases, vol. 51, no. 4, p. 641-650.

Naghawi, H. (2012), "Using Geographic Information System in Analyzing Hospital Accessibility: A Case Study in New Orleans", Jordan Journal of Civil Engineering, vol. 6, no. 3, p. 353-360.

National Institute of Statistics (2020), Tempo Online Statistics 2020, 23 April 2021 http://statistici.insse.ro:8077/tempo-online/\#/pages/tables/insse-table.

Panait, C.L. (2011), "Supply vs. demand on health services in the actual demographic context of Romania", Management in Health, vol. 15, no. 4, p. 1320.

Petrescu, E.M. and Ioncică, D.E. (2012). "Perception of private and public medical services in Romania", Contribution of Services to Economic Development, vol. 14, no. 4, p .653-664.

Pierce, R.P., Williamson, H.A. and Kruse, R.L. (1998), "Distance, use of resources, and mortality among rural Missouri residents with acute myocardial infarction", The Journal of Rural Health, no. 14, p. 28-35.

Pumain, D. and Saint-Julien, T. (2004), L'analyse spatiale - Localisations dans l'Espace, Armand Coli, Paris.

Rodrigue, J., Comtois, C. and Slack, B. (2006), The Geography of Transport Systems, Routledge, New York.

Romanian Government (2015), Law 95/2006 on Health Care Reform (Republished), Monitorul Oficial al României no. 490 and 652/2015.

Russel, L.B. (1981), "An Aging Population and the Use of Medical Care", Medical Care, vol. 19, p. 633-643.

Socharoentum, M. and Karimi, H. (2015), "A comparative analysis of routes generated by web mapping APIs", Cartography and Geographic Information Science, vol. 42, no. 1, p. 33-43.

Sotoudehnia, F. and Comber, L. (2011), "Measuring perceived accessibility to urban green space: An integration of GIS and participatory map", $14^{\text {th }}$ AGILE Conference on Geographic Information: Advancing Geoinformation Science for a Changing World, April 18-22 2011.

Spiekermann, K. and Wegner, M. (2007), Update of selected potential accessibility indicators, Final report, Urban and regional research (S\&W), RRG Spatial Planning and Geoinformation, p. 29.

Syed, T.S., Gerber, B.S. and Sharp, L.K. (2013), "Traveling Towards Disease: Transportation Barriers to Health Care Access", Journal of Community Health, vol. 38, p. 976-993. 
Tyrväinen, L., Mäkinen, K. and Schipperijn, J. (2007), "Tools for mapping social values of urban woodlands and other green areas", Landscape and Urban Planning, vol. 79, no. 1, p. 5-19.

Wang, F. (2006), Quantitative methods and applications in GIS, Taylor and Francis Group, New York, p. 304.

Wang, F. and Xu, Y. (2011), "Estimating O-D travel time matrix by Google Maps API: Implementation, advantages, and implications", Annals of GIS, vol. 17, no. 4, p. 199-209.

Weiss, D.J., Nelson, A., Gibson, H.S., Temperley, W., Peedell, S., Lieber, A., Hancher, M., Poyart, E., Belchior, S., Fullman, N., Mappin, B., Dalrymple, U., Rozier, J., Lucas, T.C.D., Howes, R.E., Tusting, L.S., Kang, S.Y., Cameron, E., Bisanzio, D., Battle, K.E., Bhatt, S. and Gething, P.W. (2018), "A global map of travel time to cities to assess inequalities in accessibility in 2015", Nature, no. 553, p. 333-336.

Wright, J. and Williams R.W.J.R. (1998), "Development and importance of health needs assessment", BMJ, p. 1310-1313. 